\title{
Computational Design of Apolipoprotein E4 Inhibitors for Alzheimer's Disease Therapy from Traditional Chinese Medicine
}

\author{
Hung-Jin Huang, ${ }^{1}$ Hsin-Yi Chen, ${ }^{2}$ Cheng-Chun Lee, ${ }^{3}$ and Calvin Yu-Chian Chen ${ }^{2,3}$ \\ ${ }^{1}$ Department of Chinese Pharmaceutical Sciences and Chinese Medicine Resources, College of Pharmacy, \\ China Medical University, Taichung 40402, Taiwan \\ ${ }^{2}$ Department of Biomedical Informatics, Asia University, Taichung 41354, Taiwan \\ ${ }^{3}$ School of Medicine, College of Medicine, China Medical University, Taichung 40402, Taiwan \\ Correspondence should be addressed to Cheng-Chun Lee; leeck@mail.cmu.edu.tw and Calvin Yu-Chian Chen; ycc929@MIT.edu
}

Received 14 February 2014; Revised 5 March 2014; Accepted 5 March 2014; Published 21 May 2014

Academic Editor: Chung Y. Hsu

Copyright (C) 2014 Hung-Jin Huang et al. This is an open access article distributed under the Creative Commons Attribution License, which permits unrestricted use, distribution, and reproduction in any medium, provided the original work is properly cited.

\begin{abstract}
Apolipoprotein E4 (Apo E4) is the major genetic risk factor in the causation of Alzheimer's disease (AD). In this study we utilize virtual screening of the world's largest traditional Chinese medicine (TCM) database and investigate potential compounds for the inhibition of ApoE4. We present the top three TCM candidates: Solapalmitine, Isodesacetyluvaricin, and Budmunchiamine L5 for further investigation. Dynamics analysis and molecular dynamics (MD) simulation were used to simulate protein-ligand complexes for observing the interactions and protein variations. Budmunchiamine L5 did not have the highest score from virtual screening; however, the dynamics pose is similar to the initial docking pose after MD simulation. Trajectory analysis reveals that Budmunchiamine L5 was stable over all simulation times. The migration distance of Budmunchiamine L5 illustrates that docked ligands are not variable from the initial docked site. Interestingly, Arg158 was observed to form $\mathrm{H}$-bonds with Budmunchiamine L5 in the docking pose and MD snapshot, which indicates that the TCM compounds could stably bind to ApoE4. Our results show that Budmunchiamine L5 has good absorption, blood brain barrier (BBB) penetration, and less toxicity according to absorption, distribution, metabolism, excretion, and toxicity (ADMET) prediction and could, therefore, be safely used for developing novel ApoE4 inhibitors.
\end{abstract}

\section{Introduction}

Alzheimer's disease (AD) is the most common harmful neurological disorder affecting patients over the age of 65 [1]. The major neuropathological hallmarks of $\mathrm{AD}$ are neurofibrillary tangles and beta amyloid plaques in the entorhinal cortex and hippocampus [2]. Deposition of $\beta$-amyloid is associated with neuronal loss and cognitive dysfunction [3], which affects the ability to study and think. There is also long-term memory loss during the life span. $\beta$-amyloid is generated from cleavage of the amyloid precursor protein (APP) by $\beta$-secretase and $\gamma$-secretase [4-8]. Several genes linked to familial $\mathrm{AD}$ have been identified in many studies, but there are still more risk-factor genes that remain to be identified [9]. The variations of apolipoprotein $\mathrm{E}(A O P E)$ genes as potential genetic risk factors for $\mathrm{AD}$ have been identified by the linkage studies of Pericak-Vance et al. [10]. The ApoE gene is located on chromosome 19q13.2, and an increase in type 4 allele of this gene is associated with several chronic neurodegenerative diseases [11].

ApoE, which exists in three different isoforms in the brain and periphery, ApoE2 (epsilon 2), ApoE3 (epsilon 3), and ApoE4 (epsilon 4), have an essential role in the regulation of cholesterol metabolism [12-14]. In human blood circulation, ApoE binds lipids and makes them soluble for transporting [13]. In the nervous system, ApoE transports cholesterol to neurons in the brain [15]. ApoE4 is the most important known genetic risk factor in the causation of sporadic $A D$ $[16,17]$, as further studies have confirmed [18], due to ApoE4 binding to $\beta$-amyloid, and transporting it to neurons. The human allele frequency of ApoE4 in Caucasian patients with $\mathrm{AD}$ is $36.7 \%$ [19]. 


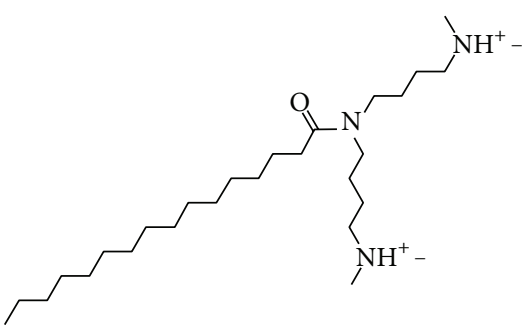

(a)<smiles>CCCC[C@H](O)[C@H]1CC[C@@H]([C@H]2CC[C@H]([C@H](O)CCCC3=C[C@H](C)OC3=O)O2)O1</smiles>

(b)

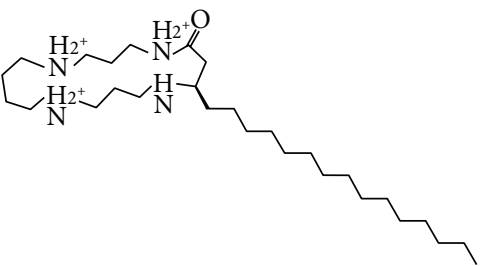

(c)

FIGURE 1: Chemical scaffold of (a) Solapalmitine, (b) Isodesacetyluvaricin, and (c) Budmunchiamine L5.

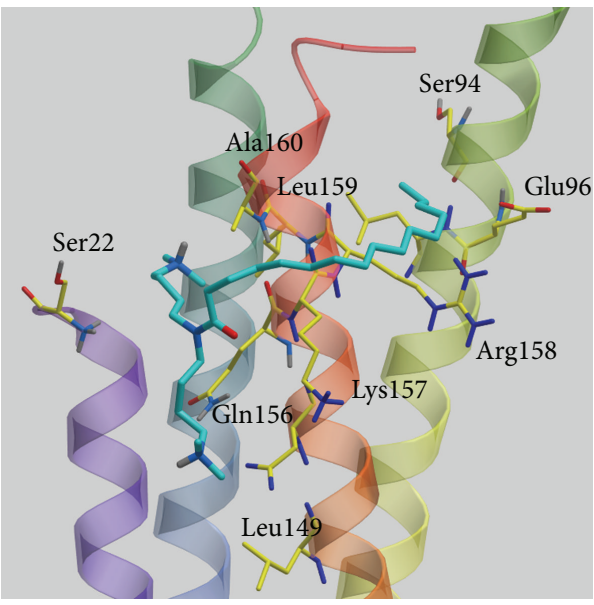

(a)

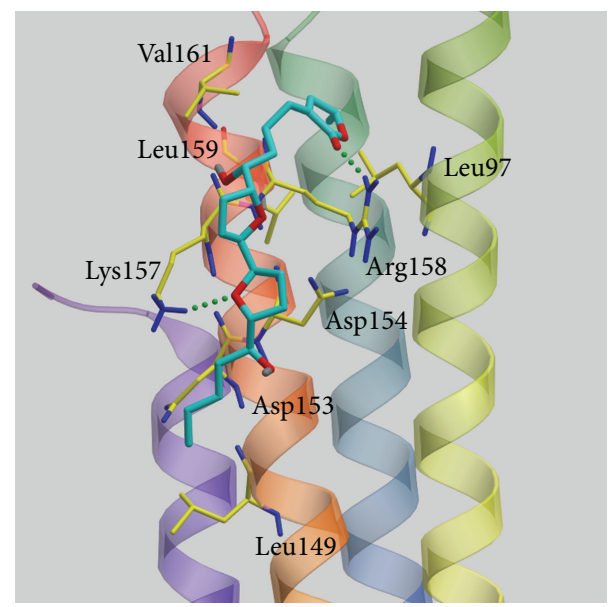

(b)

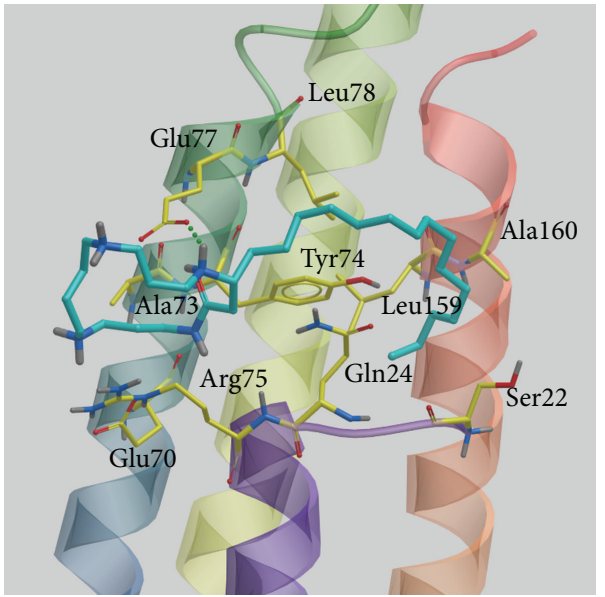

(c)

FIGURE 2: Docking poses of top three candidates: (a) Solapalmitine, (b) Isodesacetyluvaricin, and (c) Budmunchiamine L5. The small molecular and amino acids are colored in green and yellow, respectively.

We utilized computer-aided drug design (CADD) in this research in order to design potential lead drugs for $\mathrm{AD}$ therapy. CADD is an efficient approach for the rapid identification of potential lead compounds in target therapy $[20,21]$ and has been widely used in drug design including virus therapy [22-26], cancer therapy [27-31], treatment of sleeplessness [32], neuropathic therapy [33-38], weight loss therapy [39, 40], diabetic treatment [41], inflammation treatment [42], erectile dysfunction treatment [43], and hair loss therapy [44]. For target proteins, drug design should depend on some illness research [25, 41, 45-49], risk-factor studies [50-53], web server [23, 54], and scientific theories [55]; mutant proteins are also important factors as drug targets [56]. Traditional Chinese medicine (TCM) was first 


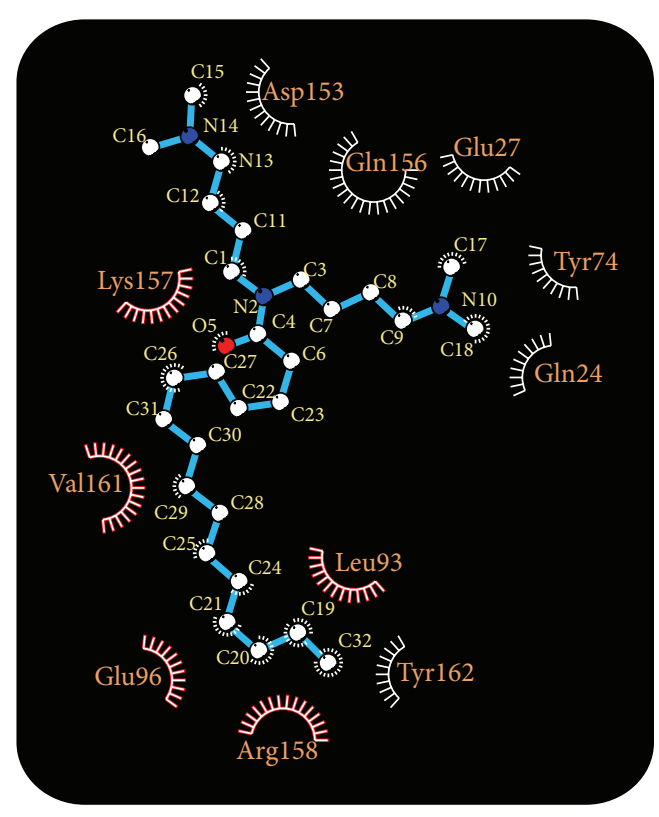

(a)

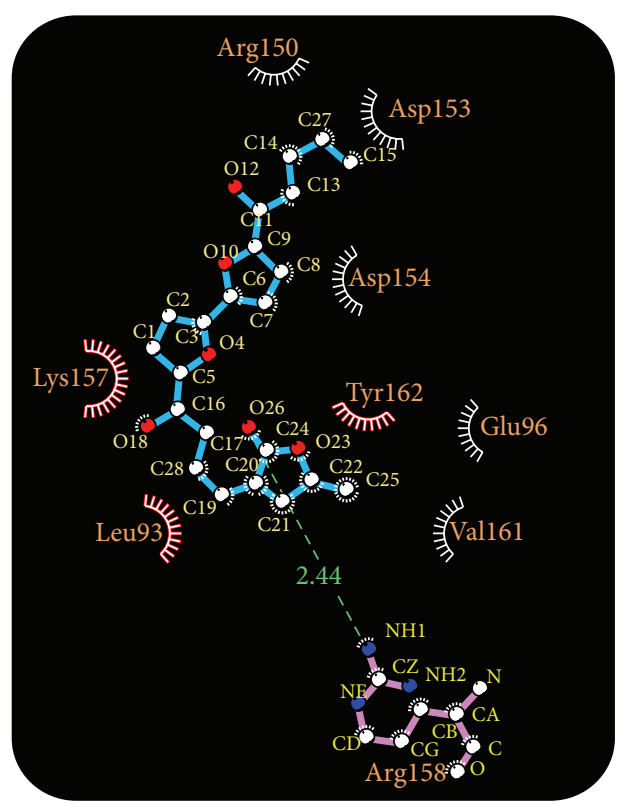

(b)
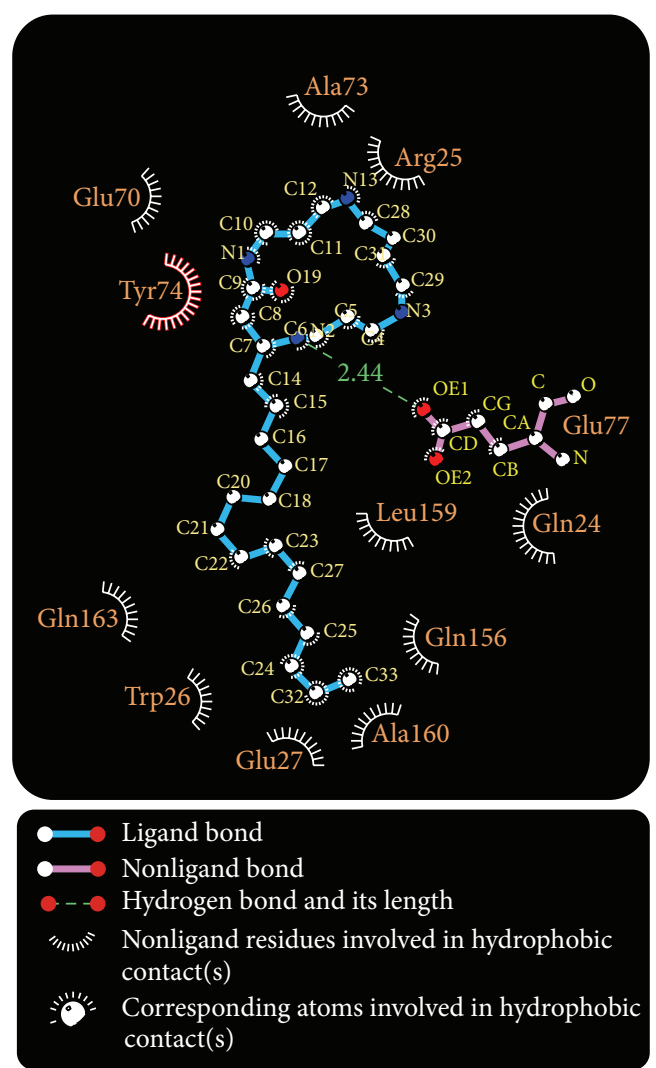

(c)

FIGURE 3: H-bond and hydrophobic analysis of docking poses by Ligplot plus tool for each docked ligand in ApoE4: (a) Solapalmitine, (b) Isodesacetyluvaricin, and (c) Budmunchiamine L5.

developed in China and has been used more than 2000 years in Asian countries. In this research, we utilize small TCM compounds from the world's largest TCM database (TCM Database@Taiwan) [57] to investigate potential lead drugs for ApoE4. The database virtual screen provides rapid search to identify potent compounds for ApoE4 interactions. Molecular dynamics (MD) simulation is used to simulate the dynamic change between ApoE4 protein and docked ligand. 


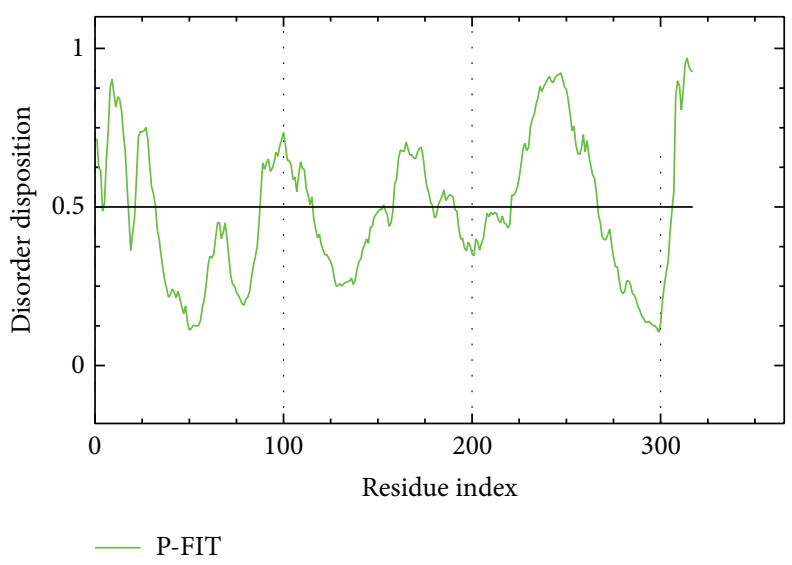

FIGURE 4: Disorder prediction of sequence of ApoE4 from the results of PONDR-FIT. The value of disorder disposition above 0.5 in disorder disposition.

TABLE 1: ADMET prediction of top ten TCM compounds from docking results.

\begin{tabular}{|c|c|c|c|c|c|}
\hline Name & LibDock score & ${ }^{\mathrm{a}}$ Absorption & ${ }^{\mathrm{b}}$ BBB Level & ${ }^{\mathrm{c}} \mathrm{CYP} 2 \mathrm{D} 6$ & ${ }^{\mathrm{d}}$ Hepatotoxicity \\
\hline Solapalmitine & 118.404 & $\mathbf{0}$ & $\mathbf{0}$ & $\mathbf{0}$ & 0 \\
\hline Isodesacetyluvaricin & 116.555 & $\mathbf{0}$ & 2 & $\mathbf{0}$ & $\mathbf{0}$ \\
\hline Budmunchiamine L5 & 116.167 & $\mathbf{0}$ & 2 & $\mathbf{0}$ & $\mathbf{0}$ \\
\hline Hemiariensin & 115.334 & 0 & 2 & 0 & 0 \\
\hline Niranthin & 112.802 & 0 & 1 & 0 & 0 \\
\hline Platyphyllonol & 112.212 & 0 & 2 & 0 & 0 \\
\hline Triptofordin B1 & 111.954 & 0 & 2 & 0 & 0 \\
\hline Aglaiduline & 111.306 & 0 & 2 & 0 & 0 \\
\hline Aurantiamide & 110.823 & 0 & 2 & 0 & 0 \\
\hline Lobelanidine & 108.696 & 0 & 2 & 0 & 0 \\
\hline
\end{tabular}

${ }^{\mathrm{a}}$ Absorption: good absorption $=0$; moderate absorption $=1$; low absorption $=2 ;{ }^{\mathrm{b} B B}$ level $($ blood brain barrier $)$ : very high penetration $=0$; high penetration $=$ 1 ; medium penetration $=2$; low penetration $=3$; undefined penetration $=4$.

${ }^{c}$ CYP2D6: noninhibitor $=0$, inhibitor $=1$.

${ }^{\mathrm{d}}$ Hepatotoxicity: noninhibitor $=0$, inhibitor $=1$.

\section{Materials and Methods}

2.1. Data Sets. We used 61,000 TCM compounds for database screening, which were obtained from TCM Database@Taiwan [57], with the drug-likeness of all compounds being predicted by ADMET prediction. The crystal structure of ApoE4 was taken from PDB database (PDB code:1GS9), the missing atoms and loops were cleaned up by Prepare Protein module under Accelrys Discovery Studio 2.5.5.9350 (DS 2.5) [58], and all residues were protonated under $\mathrm{pH} 7.4$ conditions. We also employed disorder predict tool (PONDR-FIT) [59] to predict unfolded regions on ApoE4 sequence for structure validation.

2.2. Docking Analysis. The LibDock program [60] of DS 2.5 was used to define protein site features referred to polar and nonpolar features, with a sphere of $35 \AA$ radius used as the binding area. Different rigid ligand conformations were placed into the binding area, and all ligand conformations were minimized using the CHARMm force field.
TABLE 2: Time of middle structure in each cluster from all MD simulation times.

\begin{tabular}{lccc}
\hline \multirow{2}{*}{ Cluster } & \multicolumn{3}{c}{ Time of middle flame (ps) } \\
& Solapalmitine & Isodesacetyluvaricin & Budmunchiamine L5 \\
\hline 1 & 1540 & 60 & 640 \\
2 & 4040 & 280 & 40 \\
3 & - & 1920 & 1480 \\
4 & - & 4240 & 4340 \\
\hline
\end{tabular}

Minimization performed 1000 steps of Steepest Descent with a RMS gradient tolerance of 3, which was then followed by the Conjugate Gradient. The generated ligands were docked into the defined binding site on the ApoE4 protein structure. Ligand binding in the receptor cavity was evaluated by the scoring functions of the LibDock score. Ligplot plus was used to analysis docking poses for $\mathrm{H}$-bond and hydrophobic interactions $[61,62]$. 


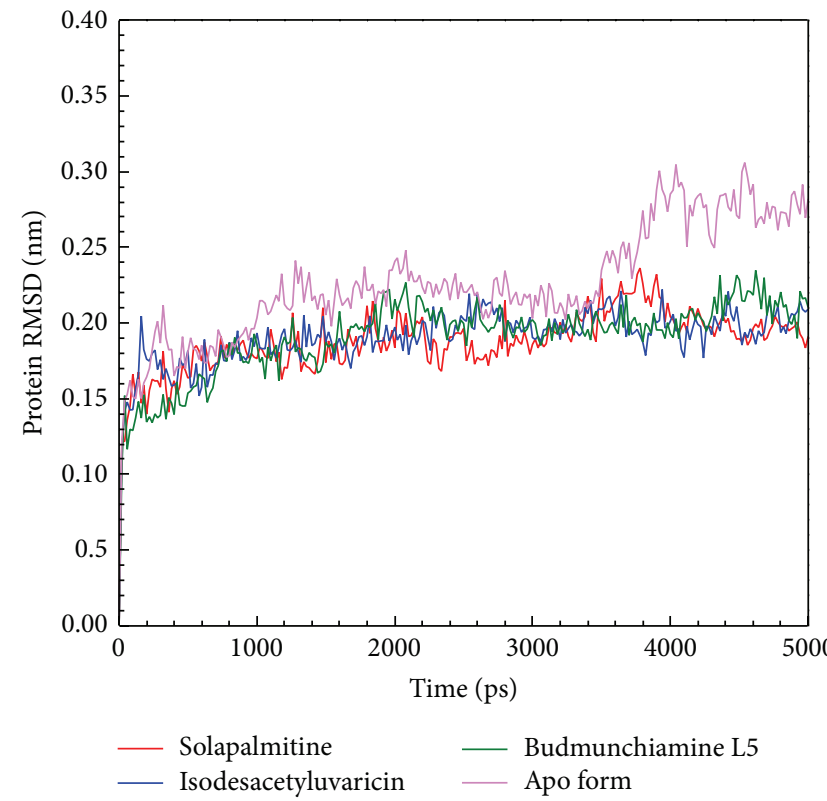

(a)

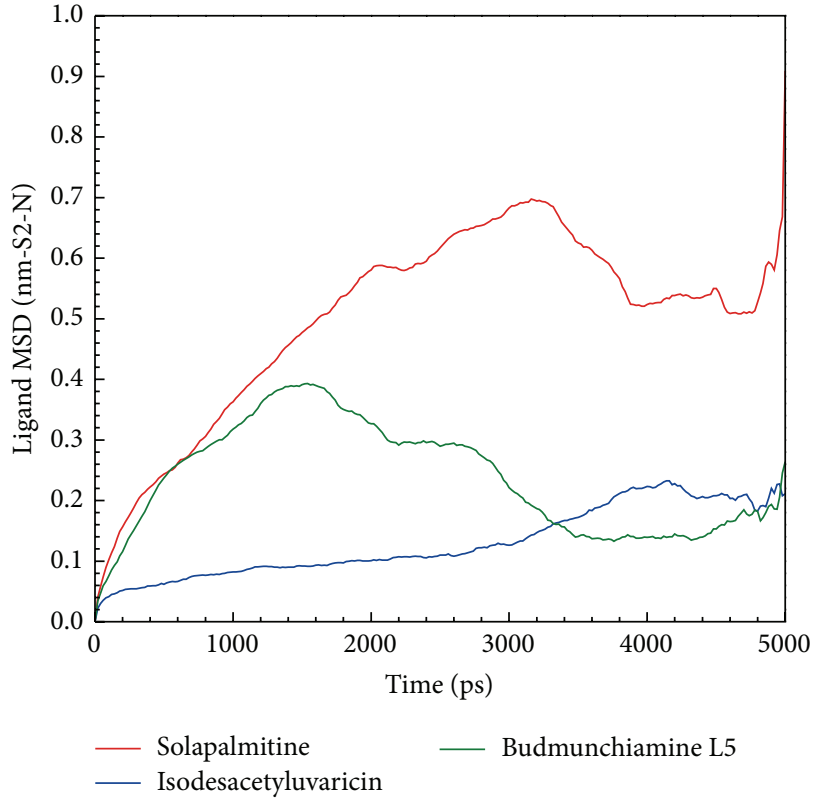

(b)

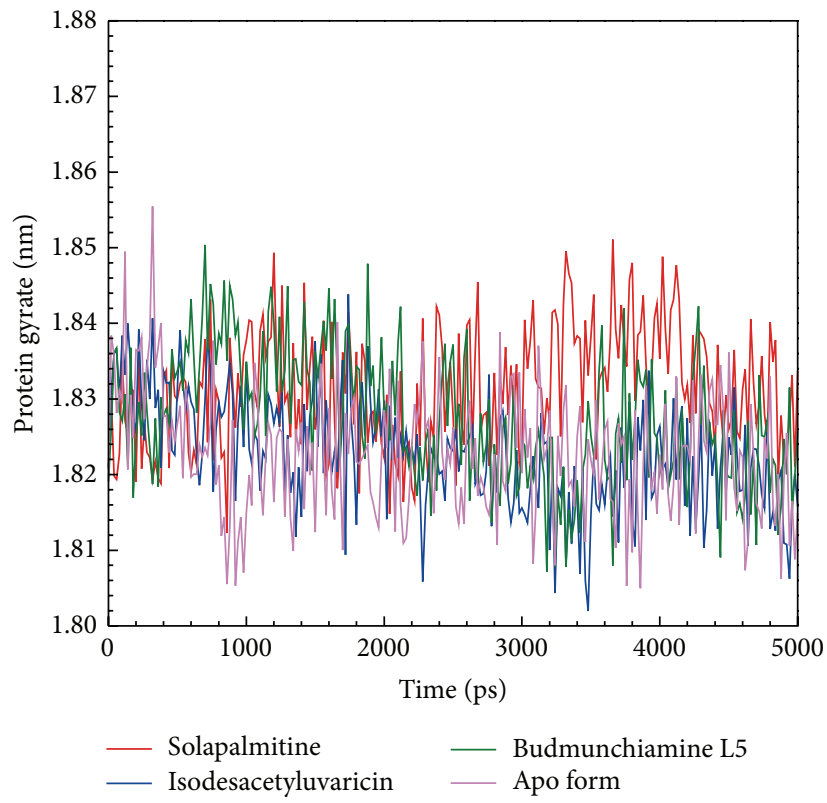

(c)

Figure 5: Plots of (a) protein RMSD, (b) ligand MSD, and (c) radius of gyration from ApoE4 with docked ligand or no ligand (apo) with a simulation time of $5000 \mathrm{ps}$.

2.3. Molecular Dynamics Simulation. The molecular dynamic simulation was performed with GROMACS 4.5.5 package [63] for protein-ligand complexes simulation and the charmm 27 force field was used in the simulation system. For box definition, distance of real space cut-off was set to $1.2 \mathrm{~nm}$. The particle mesh Ewald (PME) method was regarded as coulomb type for treating electrostatics, and the cut-off distance of defining van der Waals (VDW) residues was set at $1.4 \mathrm{~nm}$. In pair potentials versus many-body potentials
[64-67], the potential functions representing the nonbonded energy of VDW and electrostatics using the following:

$$
\begin{gathered}
U(r)=4 \varepsilon\left[\left(\frac{\delta}{\gamma}\right)^{12}-\left(\frac{\delta}{\gamma}\right)^{6}\right] \\
U_{i j}\left(r_{i j}\right)=\sum \frac{Z_{i} Z_{j}}{4 \pi \varepsilon 0} \frac{1}{r_{i j}}+\sum A_{l} \exp \frac{-r_{i j}}{P l}+\sum C_{l} r_{i j}^{-n l} .
\end{gathered}
$$




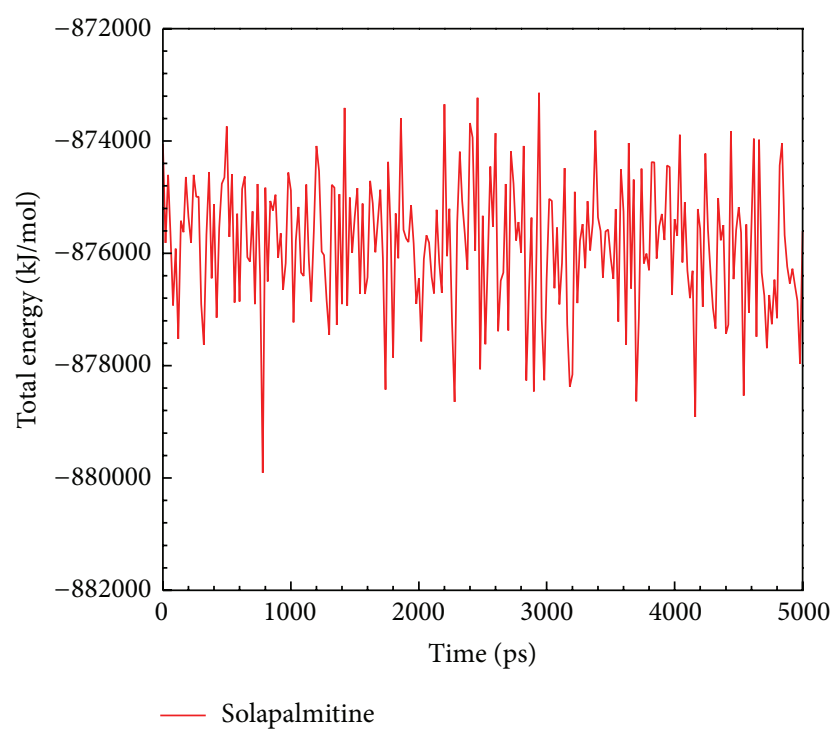

(a)

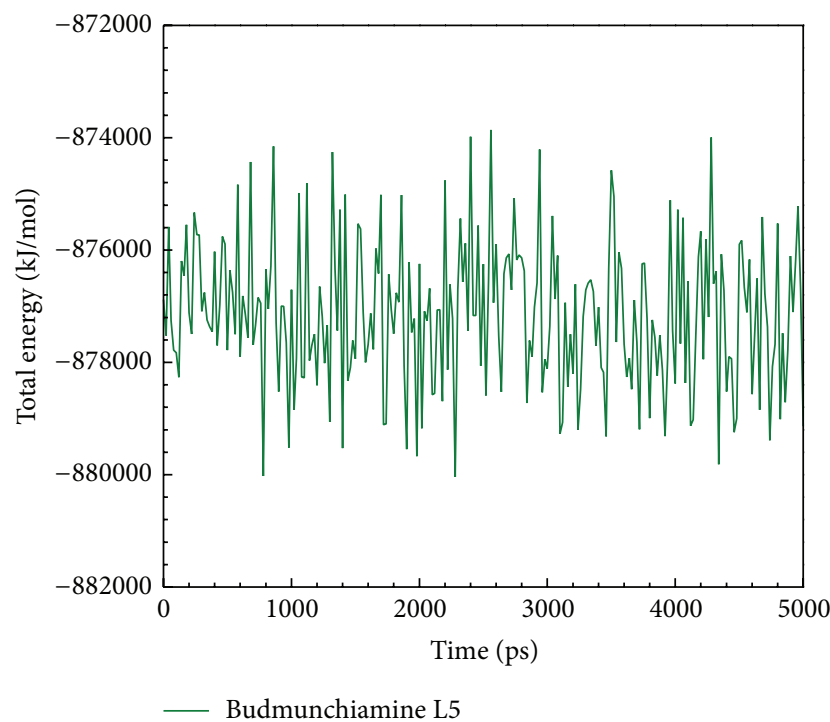

(c)

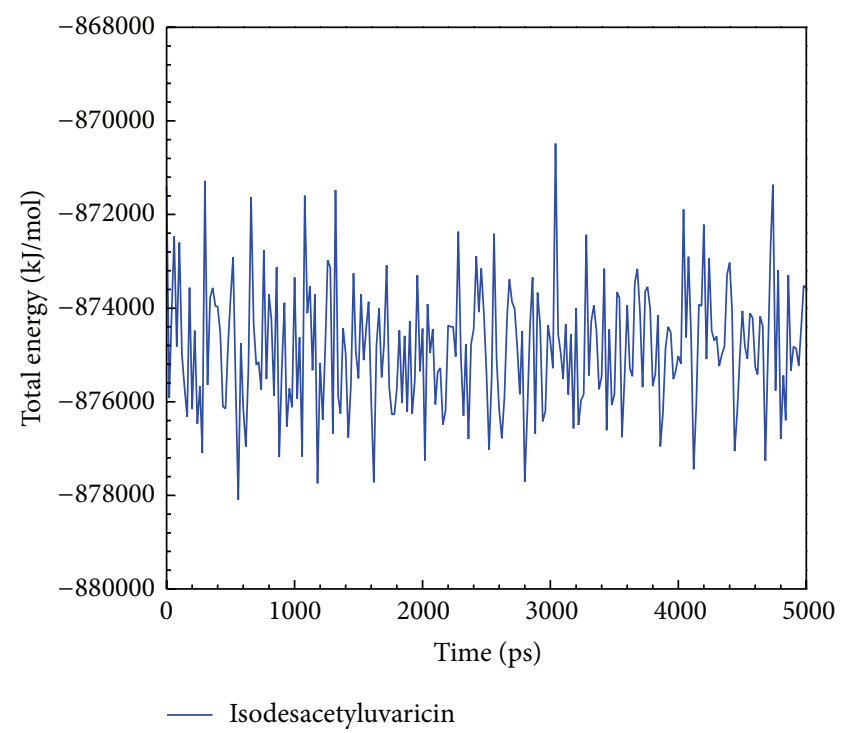

(b)

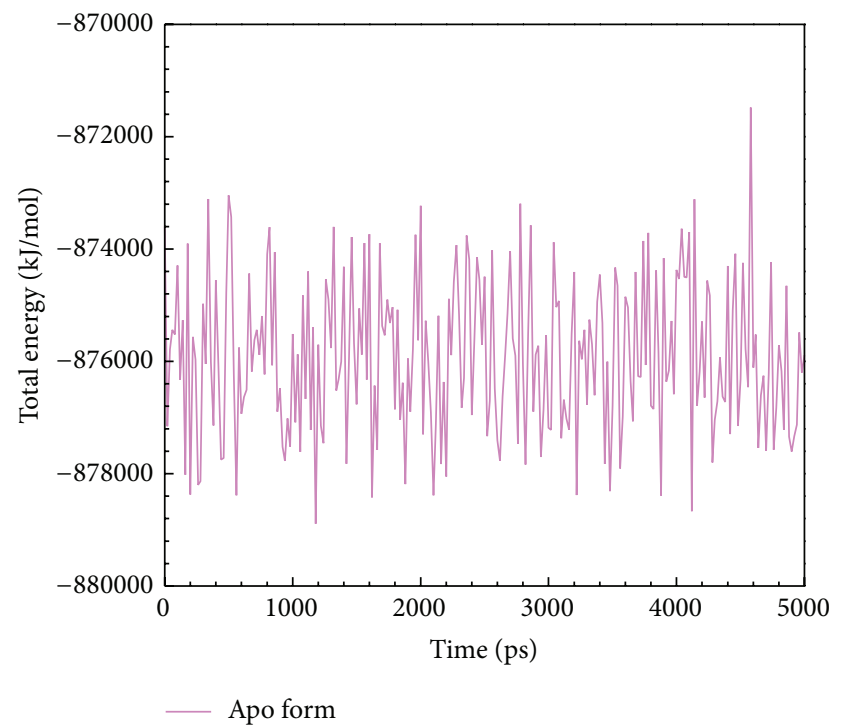

(d)

Figure 6: Total energy of ApoE4 with docked ligand: (a) Solapalmitine, (b) Isodesacetyluvaricin, and (c) Budmunchiamine L5 from all simulation times; the no-ligand binding protein (d) was used as the control.

All bonds were constrained with the linear constraint solver (LINCS) algorithm for fixing all bond lengths. The TIP3P model was employed for water simulation. Topology files and parameters of small compounds in protein-ligand complexes were generated for GROMACS simulation by the SwissParam web server; the concentration of $\mathrm{NaCl}$ model was set as $0.145 \mathrm{M}$ in the solvent system. The Steepest Descent algorithm performed the 5,000 cycle steps used for energy minimization. This was followed by equilibration performed under position restraints for 1 ns under constant temperature dynamics (NVT type) conditions. Following this step, all production dynamics simulations were performed for 5000 ps under constant pressure and temperature dynamics
(NPT type). The temperature in all of the simulation systems was set as $310 \mathrm{~K}$. MD conformations were saved every $20 \mathrm{ps}$ for trajectory analysis.

\section{Results and Discussion}

3.1. Docking Analysis. We used the LibDock score to select potent TCM compounds which have high affinity with ApoE4. The results of the docking score are listed in Table 1 and all candidates are ranked by LibDock Score. We also used ADMET prediction to evaluate the drug-likeness of TCM candidates. All TCM candidates had a good absorption prediction for metabolism. In toxicity evaluation no TCM 


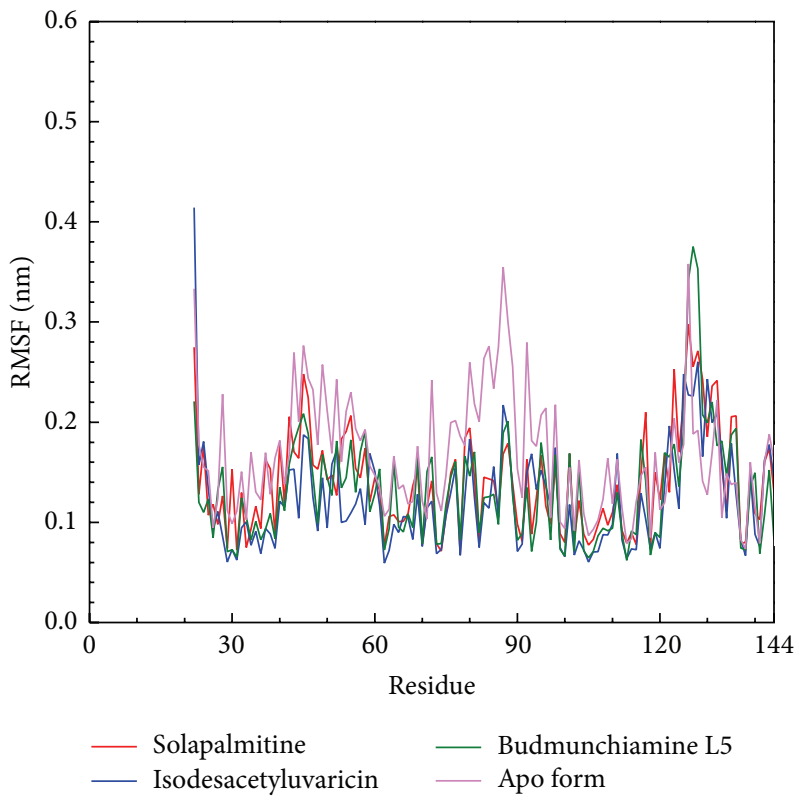

Figure 7: RMSF values of ApoE4 with docked ligand or no ligand (Apo) (a) Solapalmitine, (b) Isodesacetyluvaricin, and (c) Budmunchiamine L5 with simulation times of 5000 ps; the no-ligand binding protein (d) was used as the control.

candidate displayed CYP2D6 inhibiting and hepatotoxicity, suggesting that these ligands have no toxicity in the liver. Blood brain barrier (BBB) penetration showed that these ligands have good penetration and may be suitable for central nerve system therapy. We regard the top three TCM candidates, Solapalmitine, Isodesacetyluvaricin, and Budmunchiamine L5, as potential compounds and further analyze the binding poses in ApoE4 protein structure. Scaffold of the top three TCM compounds is shown in Figure 1, and the docking poses of each ligand are displayed in Figure 2. For $\mathrm{H}$-bond analysis, Solapalmitine had no $\mathrm{H}$-bonds with any residue of ApoE4. The docking pose of Isodesacetyluvaricin revealed H-bonds with Lys157 and ARG158. For Budmunchiamine L5, the docked ligand formed two H-bonds with Glu77. In the 2D diagram of docking poses by Ligplot (Figure 3), Solapalmitine did not reveal any $\mathrm{H}$-bonds, while the surrounding residues, Asp153, Gln156, Gln27, Tyr74, Gln24, Lys157, Val161, Leu93, Tyr162, Glu96, and Arg158, displayed hydrophobic interactions with the ligand. The 2D diagram of Isodesacetyluvaricin was similar to the 3D docking poses, which form H-bond with Arg158; hydrophobic interaction residues included Arg150, Asp153, Asp154, Tyr162, GLu96, Val161, Lys157, Leu93, and Arg158. For Budmunchiamine L5, the $2 \mathrm{D}$ diagram is corrected with $3 \mathrm{D}$ docking pose, and only Glu77 can form H-bonds with the docked ligand; this ligand also interacted with Ala73, Arg25, Glu70, Tyr74, Glu77, Gln24, Leu159, Gln156, Ala160, Glu27, Trp26, and Gln163 by hydrophobic forces.

In comparison with the docking study, PONDR-FIT was used to predict the disorder region among all residues on ApoE4 (Figure 4). According to the drug design of protein structure [68], ordered folding regions do not influence ligand binding $[69,70]$. Most of binding residues for the top three compounds were below 0.5, suggesting that the structure of ApoE4 will not affect ligands binding to the active site. To further analyze the variation of the docked protein structure, we utilized MD simulation to generate a dynamic structure for binding analysis of the top three TCM compounds.

3.2. Stability Analysis. Complexes of ApoE4 with docked ligands were performed by MD simulation at $5000 \mathrm{ps}$, and ApoE4 with no ligand (Apo protein) were regarded as the control for comparison. Each plot of the root mean square deviation (RMSD), mean square displacement (MSD), and radius of gyration $\left(R_{g}\right)$ is displayed in Figure 5. The Apo protein of ApoE4 changed significantly from 0.20 to $0.27 \mathrm{~nm}$ after 4000 ps, indicating that ApoE4 with ligand was more stable during MD simulation. The MSD analysis was used to calculate the migration distance among all simulation times. The MSD values for Budmunchiamine L5 increased from 1500 to 5000 ps, which displayed a similar movement distance to Isodesacetyluvaricin at final simulation time. Solapalmitine had an increased MSD value with a simulation time of 5000 ps, suggesting that Solapalmitine is less stable than the other two TCM candidates. The gyration assay was used to analyze the compactness of protein structure. $R_{g}$ values of all protein-ligand complexes and Apo protein had similar fluctuations, indicating all structures tended to become stable after MD simulation. For total energy analysis, no significantly increased values were observed among all simulation times (Figure 6). The total energy of all systems remained in $-876000 \mathrm{~kJ} / \mathrm{mol}$. These results suggest that all 


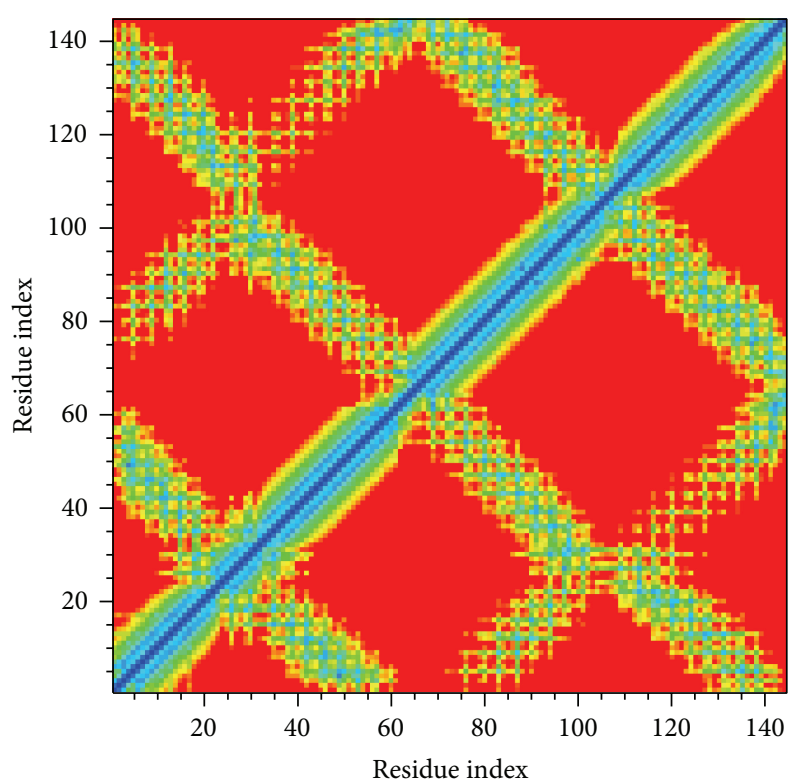

(a)

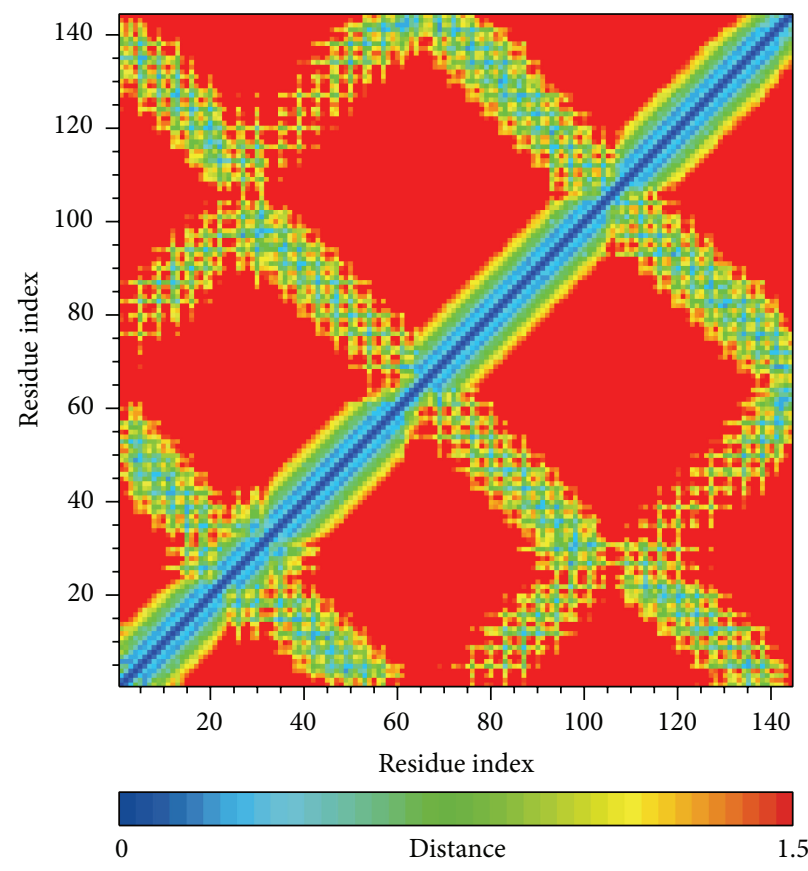

(c)

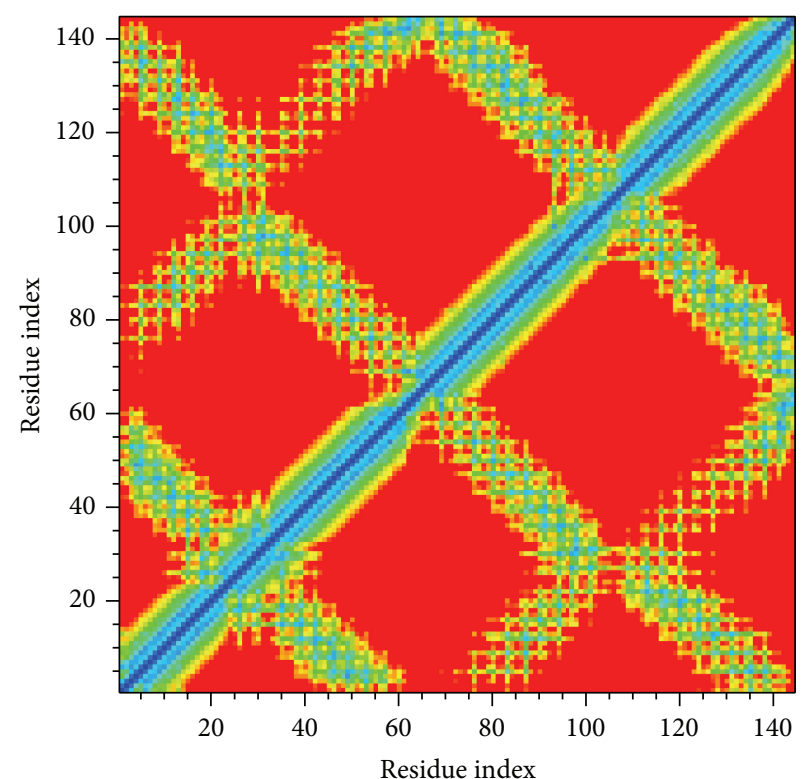

(b)

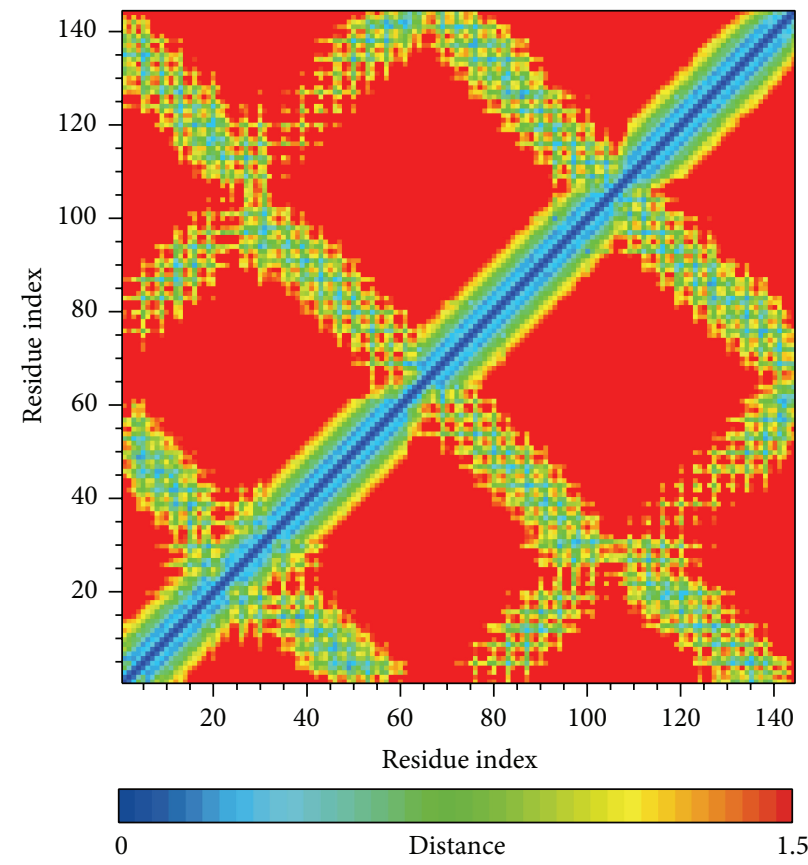

(d)

Figure 8: Matrix of smallest distance between each pair of amino acids in the complex with (a) Solapalmitine, (b) Isodesacetyluvaricin, and (c) Budmunchiamine L5; the no-ligand binding protein (d) is used as the control.

structures of the complexes tend to become constant after the initial simulation time.

3.3. Residues Fluctuation and Distance Analysis. Root mean squared fluctuation (RMSF) was carried out to analyze the fluctuation of residues on ApoE4 protein (Figure 7). It is obvious that residues of Apo proteinfrom 70 to 100 exhibit substantial fluctuation, but the three candidates remain stable.
The ligand binding region is included in this region, but the docked residues are not flexible due to the largest fluctuations being exhibited at terminal residues, and these regions are far from the docked residues. The results suggest that the docked ligand could bind stably to ApoE4. The matrices of distance maps for residue-residue distance calculations over 5000 ps are shown in Figure 8. The results display that all complexes with docked ligands are the same as Apo protein, suggesting that the conformations do change among all MD simulations. 

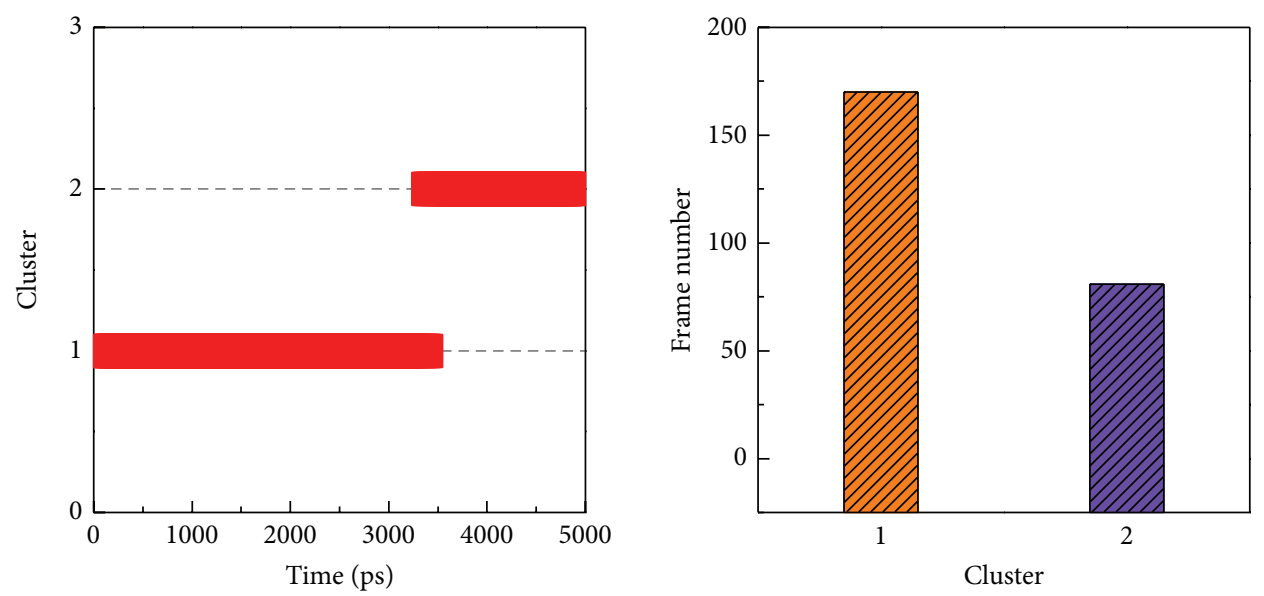

(a)
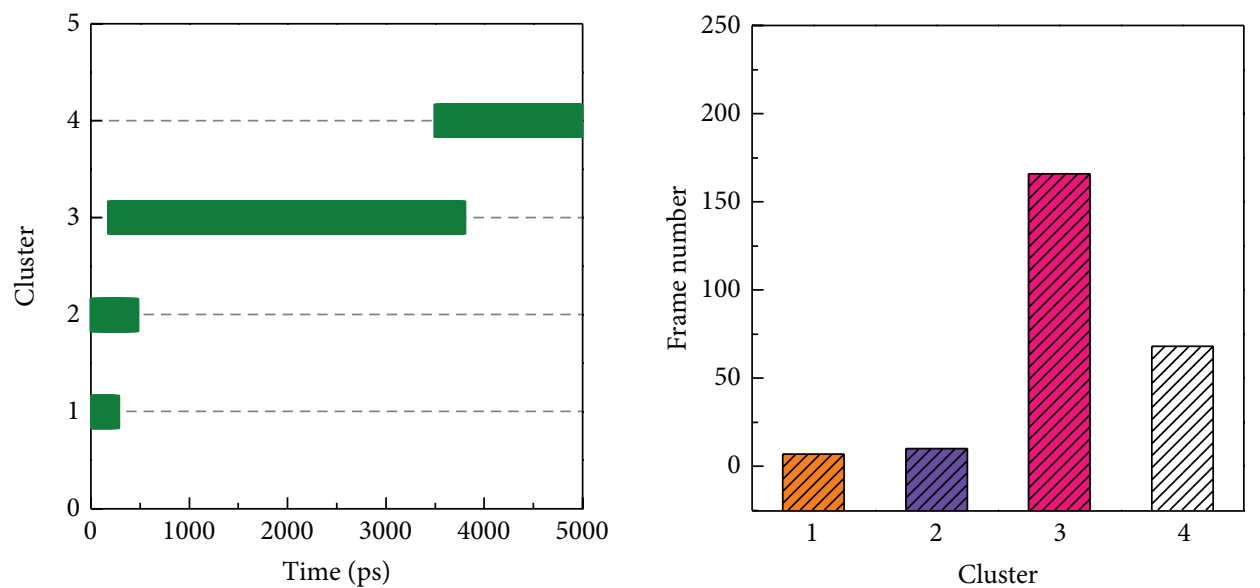

(b)
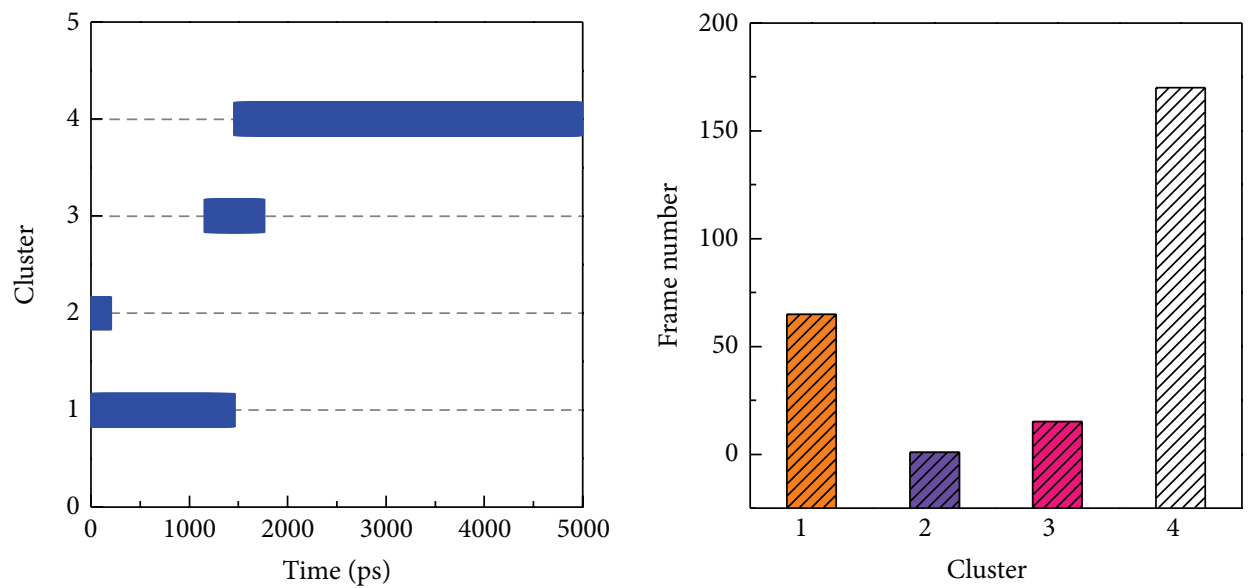

(c)

FIGURE 9: Clustering analyses of protein conformations: (a) Solapalmitine, (b) Isodesacetyluvaricin, and (c) Budmunchiamine L5 with simulation times of 5000 ps. 


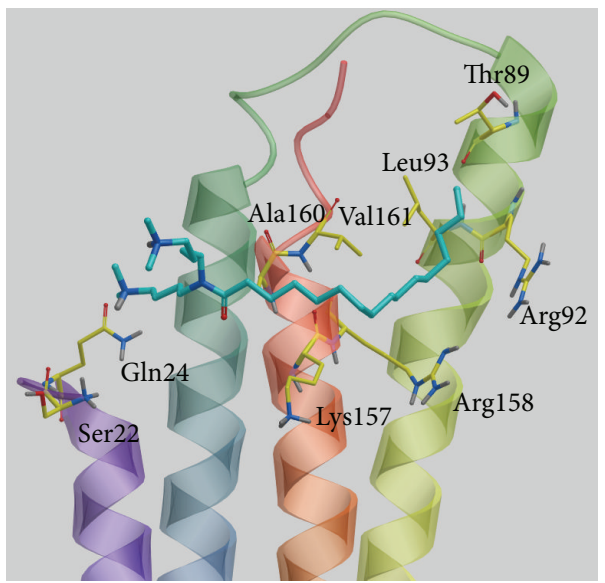

(a)

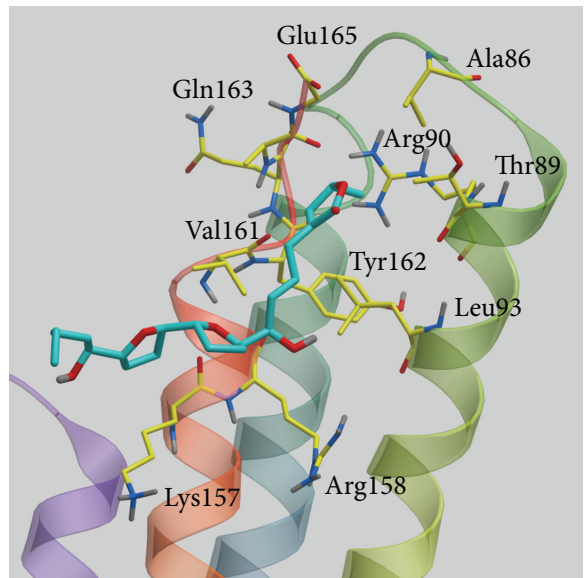

(b)

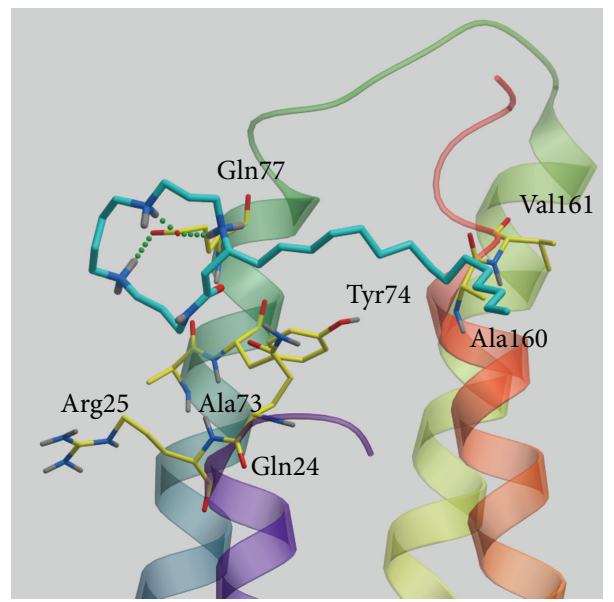

(c)

FIGURE 10: The middle structure from each final clustering group with docked ligand: (a) Solapalmitine, (b) Isodesacetyluvaricin, and (c) Budmunchiamine L5. The small molecular and amino acids are colored green and yellow, respectively.

3.4. Clustering Analysis for Snapshot Selection. A cluster algorithm was employed to select the most stable conformation over all simulation times. All MD snapshots with docked ligands were grouped into two or four individual clusters (Figure 9) with each cluster including similar conformations. The middle structure was chosen from each late group as a standard snapshot for the binding analysis of the top three TCM compounds: Solapalmitine (4040 ps), Isodesacetyluvaricin (4240 ps), and Budmunchiamine L5 (4340 ps) (Table 2). In the binding analysis from the standard snapshot (Figure 10), we found that Budmunchiamine L5 exhibited H-bond interaction with Glu77, but the H-bonds disappeared between Isodesacetyluvaricin and Arg158. Solapalmitine continued to have no $\mathrm{H}$-bond interactions between residues. The data shows that Glu77 is a crucial residue for Budmunchiamine L5 binding. We also employed CAVER 3.0 software [71] to analyze the migrated ligand tunnels in ApoE4 (Figure 11), and the ligand pathway analysis was used to predict in previous studies [40]. The prediction of ApoE4 showed lower number of channels than Apo form of ApoE4; the results illustrated that the TCM candidates could form stable binding conformation to interact with ApoE4 with all simulation time.

\section{Conclusion}

Solapalmitine is the top candidate by LibDock score but displays significantly increasing MSD values due to unstable binding with ApoE4 over 5000 ps simulation time. Isodesacetyluvaricin has $\mathrm{H}$-bond with Arg158; unfortunately, the $\mathrm{H}$-bond is missing during MD simulation. The LibDock score of Budmunchiamine L5 is not the highest score from the TCM database screening; however, the dynamics simulation shows that the docked ligand complex of ApoE4 is stable. In snapshot analysis, Budmunchiamine L5 still forms an $\mathrm{H}$ bond with Glu77; the binding pose is the same as the initial docking pose, suggesting that Budmunchiamine L5 does not change over all simulation times and stably binds to ApoE4. In terms of ADMET analysis, Budmunchiamine L5 has good absorption, $\mathrm{BBB}$ penetration, and less toxicity in the human 


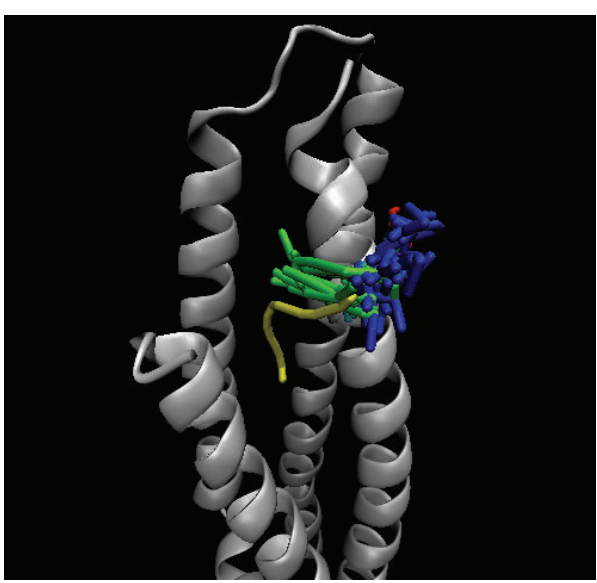

(a)

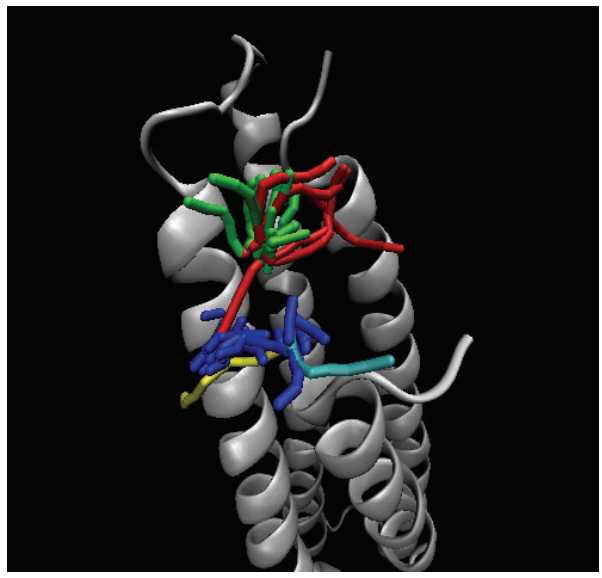

(c)

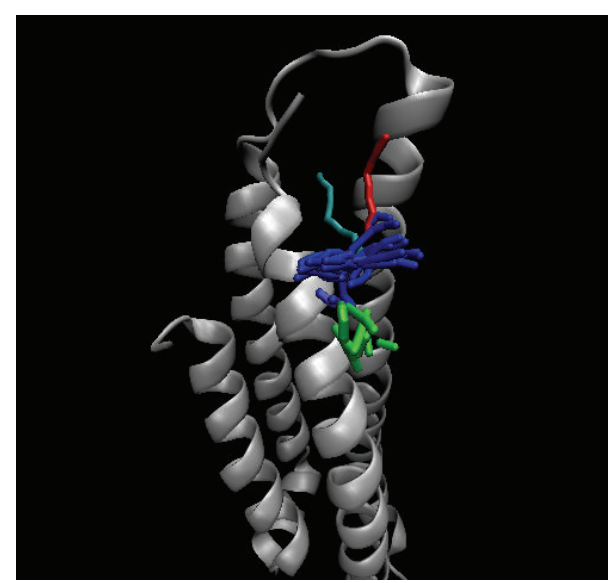

(b)

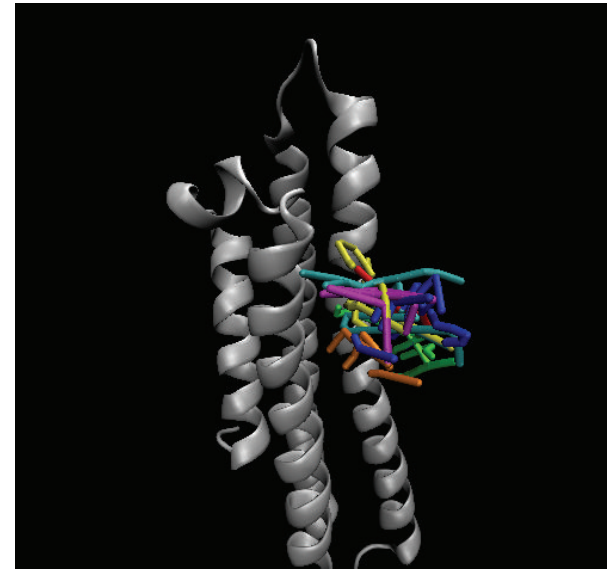

(d)

FIGURE 11: Ligand pathway prediction form protein conformations: (a) Solapalmitine, (b) Isodesacetyluvaricin, and (c) Budmunchiamine L5 and (d) Apo form of APOE4 with simulation times of 5000 ps.

liver and may therefore be regarded as a safe lead drug for designing a novel ApoE4 inhibitor for AD therapy.

\section{Conflict of Interests}

The authors declare that there is no conflict of interests.

\section{Authors' Contribution}

Hung-Jin Huang and Hsin-Yi Chen contributed equally to this work.

\section{Acknowledgments}

The research was supported by grants from the National Science Council of Taiwan (NSC102-2325-B039-001, NSC102-2221-E-468-027-), Asia University (ASIA100-CMU2, ASIA101-CMU-2, 102-ASIA-07), and China Medical University Hospital (DMR-102-051, DMR-103-058, DMR103-001, DMR-103-096). This study is also supported in part by Taiwan Department of Health Clinical Trial and Research Center of Excellence (DOH102-TD-B-111-004), Taiwan
Department of Health Cancer Research Center of Excellence (MOHW103-TD-B-111-03), and CMU under the Aim for Top University Plan of the Ministry of Education, Taiwan. Our gratitude goes to Tim Williams, Asia University.

\section{References}

[1] R. L. Nussbaum and C. E. Ellis, "Alzheimer's disease and Parkinson's disease," The New England Journal of Medicine, vol. 348, no. 14, pp. 1356-1364, 2003.

[2] H. Braak and E. Braak, "Staging of Alzheimer's disease-related neurofibrillary changes," Neurobiology of Aging, vol. 16, no. 3, pp. 271-278, 1995.

[3] T. Gomez-Isla, R. Hollister, H. West et al., "Neuronal loss correlates with but exceeds neurofibrillary tangles in Alzheimer's disease," Annals of Neurology, vol. 41, no. 1, pp. 17-24, 1997.

[4] J. Hardy, "Alzheimer's disease: the amyloid cascade hypothesis: an update and reappraisal," Journal of Alzheimer's Disease, vol. 9, supplement, no. 3, pp. 151-153, 2006.

[5] S. Silhol, A. Calenda, V. Jallageas et al., "beta-Amyloid protein precursor in Microcebus murinus: genotyping and brain localization," Neurobiology of Disease, vol. 3, no. 3, pp. 169-182, 1996. 
[6] I. Dewachter, D. Reversé, N. Caluwaerts et al., "Neuronal deficiency of presenilin 1 inhibits amyloid plaque formation and corrects hippocampal long-term potentiation but not a cognitive defect of amyloid precursor protein [V7171] transgenic mice," Journal of Neuroscience, vol. 22, no. 9, pp. 3445-3453, 2002.

[7] M. M. Verbeek, I. Otte-Höller, J. A. M. Fransen, and R. M. W. de Waal, "Accumulation of the amyloid- $\beta$ precursor protein in multivesicular body-like organelles," Journal of Histochemistry and Cytochemistry, vol. 50, no. 5, pp. 681-690, 2002.

[8] L. Torroja, H. Chu, I. Kotovsky, and K. White, "Neuronal overexpression of APPL, the Drosophila homologue of the amyloid precursor protein (APP), disrupts axonal transport," Current Biology, vol. 9, no. 9, pp. 489-492, 1999.

[9] L. Bertram, M. B. McQueen, K. Mullin, D. Blacker, and R. E. Tanzi, "Systematic meta-analyses of Alzheimer disease genetic association studies: the AlzGene database," Nature Genetics, vol. 39, no. 1, pp. 17-23, 2007.

[10] M. A. Pericak-Vance, J. L. Bebout, P. C. Gaskell Jr. et al., "Linkage studies in familial Alzheimer disease: evidence for chromosome 19 linkage," The American Journal of Human Genetics, vol. 48, no. 6, pp. 1034-1050, 1991.

[11] W. J. Strittmatter, A. M. Saunders, D. Schmechel et al., "Apolipoprotein E: high-avidity binding to $\beta$-amyloid and increased frequency of type 4 allele in late-onset familial Alzheimer disease," Proceedings of the National Academy of Sciences of the United States of America, vol. 90, no. 5, pp. 19771981, 1993.

[12] L. A. Johnson, R. H. J. Olsen, L. S. Merkens et al., "Apolipoprotein E-low density lipoprotein receptor interaction affects spatial memory retention and brain ApoE levels in an isoformdependent manner," Neurobiology of Disease, vol. 64, pp. 150$162,2014$.

[13] A. D. Roses, "Apolipoprotein E and Alzheimer's disease. The tip of the susceptibility iceberg," Annals of the New York Academy of Sciences, vol. 855, pp. 738-743, 1998.

[14] C. E. Finch, "Evolution of the human lifespan and diseases of aging: roles of infection, inflammation, and nutrition," Proceedings of the National Academy of Sciences of the United States of America, vol. 107, supplement 1, pp. 1718-1724, 2010.

[15] R. W. Mahley and S. C. Rall Jr., "Apolipoprotein E: far more than a lipid transport protein," Annual Review of Genomics and Human Genetics, vol. 1, no. 2000, pp. 507-537, 2000.

[16] W. M. van der Flier, Y. A. Pijnenburg, N. C. Fox, and P. Scheltens, "Early-onset versus late-onset Alzheimer's disease: the case of the missing APOE $\varepsilon 4$ allele," The Lancet Neurology, vol. 10, no. 3, pp. 280-288, 2011.

[17] L. Ungar, A. Altmann, and M. D. Greicius, "Apolipoprotein E, gender, and Alzheimer's disease: an overlooked, but potent and promising interaction," Brain Imaging and Behavior, vol. 8, no. 2, pp. 262-273, 2014.

[18] E. H. Corder, A. M. Saunders, W. J. Strittmatter et al., "Gene dose of apolipoprotein E type 4 allele and the risk of Alzheimer's disease in late onset families," Science, vol. 261, no. 5123, pp. 921923, 1993.

[19] L. A. Farrer, L. Cupples, J. L. Haines et al., "Effects of age, sex, and ethnicity on the association between apolipoprotein e genotype and alzheimer disease: a meta-analysis," JAMA: Journal of the American Medical Association, vol. 278, no. 16, pp. 1349-1356, 1997.
[20] C. Y. Chen, "A novel integrated framework and improved methodology of computer-aided drug design," Current Topics in Medicinal Chemistry, vol. 13, no. 9, pp. 965-988, 2013.

[21] H.-J. Huang, H. W. Yu, C.-Y. Chen et al., "Current developments of computer-aided drug design," Journal of the Taiwan Institute of Chemical Engineers, vol. 41, no. 6, pp. 623-635, 2010.

[22] H. J. Huang, Y. R. Jian, and C. Y. Chen, "Traditional chinese medicine application in HIV: an in silico study," Journal of Biomolecular Structure and Dynamics, vol. 32, no. 1, pp. 1-12, 2014.

[23] K.-W. Chang, T.-Y. Tsai, K.-C. Chen et al., "iSMART: an integrated cloud computing web server for traditional Chinese medicine for online virtual screening, de novo evolution and drug design," Journal of Biomolecular Structure and Dynamics, vol. 29, no. 1, pp. 243-250, 2011.

[24] S.-S. Chang, H.-J. Huang, and C. Y.-C. Chen, "High performance screening, structural and molecular dynamics analysis to identify H1 inhibitors from TCM Database@Taiwan," Molecular BioSystems, vol. 7, no. 12, pp. 3366-3374, 2011.

[25] T.-T. Chang, M.-F. Sun, H.-Y. Chen et al., "Screening from the world's largest TCM database against H1N1 virus," Journal of Biomolecular Structure and Dynamics, vol. 28, no. 5, pp. 773786, 2011.

[26] C.-H. Lin, T.-T. Chang, M.-F. Sun et al., "Potent inhibitor design against H1N1 swine influenza: structure-based and molecular dynamics analysis for M2 inhibitors from traditional Chinese medicine database," Journal of Biomolecular Structure and Dynamics, vol. 28, no. 4, pp. 471-482, 2011.

[27] Y. A. Tsou, K. C. Chen, H. C. Lin, S. S. Chang, and C. Y. Chen, "Uroporphyrinogen decarboxylase as a potential target for specific components of traditional Chinese medicine: a virtual screening and molecular dynamics study," PLOS ONE, vol. 7, no. 11, Article ID e50087, 2012.

[28] S.-C. Yang, S.-S. Chang, and C. Y.-C. Chen, "Identifying HER2 inhibitors from natural products database," PLoS ONE, vol. 6, no. 12, Article ID e28793, 2011.

[29] S.-C. Yang, S.-S. Chang, H.-Y. Chen, and C. Y.-C. Chen, "Identification of potent EGFR inhibitors from TCM Database@Taiwan," PLoS Computational Biology, vol. 7, no. 10, Article ID e1002189, 2011.

[30] C.-Y. Chen and C. Y.-C. Chen, "Insights into designing the dual-targeted HER2/HSP90 inhibitors," Journal of Molecular Graphics and Modelling, vol. 29, no. 1, pp. 21-31, 2010.

[31] W. I. Tou and C. Y. Chen, "In silico investigation of potential SRC kinase ligands from traditional Chinese medicine," PLoS ONE, vol. 7, no. 3, Article ID e33728, 2012.

[32] H. Y. Chen, S. S. Chang, Y. C. Chan, and C. Y. Chen, "Discovery of novel insomnia leads from screening traditional Chinese medicine database," Journal of Biomolecular Structure and Dynamics, vol. 32, no. 5, pp. 776-791, 2014.

[33] K.-C. Chen, K.-W. Chang, H.-Y. Chen, and C. Y.-C. Chen, "Traditional Chinese medicine, a solution for reducing dual stroke risk factors at once?" Molecular BioSystems, vol. 7, no. 9, pp. 2711-2719, 2011.

[34] I. C. Hung, S. S. Chang, P. C. Chang, C. C. Lee, and C. Y. Chen, "Memory enhancement by traditional Chinese medicine?" Journal of Biomolecular Structure and Dynamics, vol. 31, no. 12, pp. 1411-1439, 2013.

[35] T.-T. Chang, K.-C. Chen, K.-W. Chang et al., "In silico pharmacology suggests ginger extracts may reduce stroke risks," Molecular BioSystems, vol. 7, no. 9, pp. 2702-2710, 2011. 
[36] K. C. Chen, Y. R. Jian, M. F. Sun et al., "Investigation of silent information regulator 1 (Sirtl) agonists from Traditional Chinese Medicine," Journal of Biomolecular Structure and Dynamics, vol. 31, no. 11, pp. 1207-1218, 2013.

[37] K.-C. Chen and C. Yu-Chian Chen, "Stroke prevention by traditional Chinese medicine? A genetic algorithm, support vector machine and molecular dynamics approach," Soft Matter, vol. 7, no. 8, pp. 4001-4008, 2011.

[38] H. J. Huang, C. C. Lee, and C. Y. C. Chen, "Pharmacological chaperone design for reducing risk factor of Parkinson's disease from traditional Chinese medicine," Evidence-Based Complementary and Alternative Medicine, vol. 2014, Article ID 830490, 12 pages, 2014.

[39] K. Y. Chen, S. S. Chang, and C. Y. Chen, "In silico identification of potent pancreatic triacylglycerol lipase inhibitors from traditional Chinese medicine," PLoS ONE, vol. 7, no. 9, Article ID e43932, 2012.

[40] K. C. Chen, S. S. Chang, H. J. Huang et al., "Three-in-one agonists for PPAR-alpha, PPAR-gamma, and PPAR-delta from traditional Chinese medicine," Journal of Biomolecular Structure and Dynamics, vol. 30, no. 6, pp. 662-683, 2012.

[41] K. C. Chen, S. S. Chang, F. J. Tsai, and C. Y. Chen, "Han ethnicity-specific type 2 diabetic treatment from traditional Chinese medicine?" Journal of Biomolecular Structure and Dynamics, vol. 31, no. 11, pp. 1219-1235, 2013.

[42] K.-C. Chen, M.-F. Sun, S.-C. Yang et al., "Investigation into potent inflammation inhibitors from traditional Chinese medicine," Chemical Biology and Drug Design, vol. 78, no. 4, pp. 679-688, 2011.

[43] C. Y.-C. Chen, "Computational screening and design of traditional Chinese medicine (TCM) to block phosphodiesterase-5," Journal of Molecular Graphics and Modelling, vol. 28, no. 3, pp. 261-269, 2009.

[44] H. J. Huang and C. Y. Chen, "A possible solution for hairloss by inhibiting corticotropin-releasing factor (CRF) receptor from traditional Chinese medicine," Journal of Biomolecular Structure and Dynamics, 2014.

[45] Y. T. Chang, W. D. Lin, Z. N. Chin et al., "Nonketotic hyperglycinemia: a case report and brief review," BioMedicine, vol. 2, no. 2, pp. 80-82, 2012.

[46] W. L. Liao and F. J. Tsai, "Personalized medicine: a paradigm shift in healthcare," BioMedicine, vol. 3, no. 2, pp. 66-72, 2013.

[47] D. Y. Lin, F. J. Tsai, C. H. Tsai, and C. Y. Huang, "Mechanisms governing the protective effect of 17beta-estradiol and estrogen receptors against cardiomyocyte injury," BioMedicine, vol. 1, no. 1, pp. 21-28, 2011.

[48] F. J. Tsai, "Rare diseases: a mysterious puzzle," BioMedicine, vol. 3, no. 2, pp. 65-104, 2013.

[49] C. H. Wang, W. D. Lin, and F. J. Tsai, "Craniofacial dysmorphism, what is your diagnosis?” BioMedicine, vol. 2, no. 2, pp. 49-50, 2012.

[50] I. C. Chou, W. D. Lin, C. H. Wang et al., "Möbius syndrome in a male with XX/XY mosaicism," BioMedicine, vol. 3, no. 2, pp. 102-104, 2013.

[51] I. C. Chou, W. D. Lin, C. H. Wang et al., "Association analysis between Tourette's syndrome and two dopamine genes (DAT1, DBH) in Taiwanese children," BioMedicine, vol. 3, no. 2, pp. 8891, 2013.

[52] W. Y. Lin, H. P. Liu, J. S. Chang et al., "Genetic variations within the PSORS1 region affect Kawasaki disease development and coronary artery aneurysm formation," BioMedicine, vol. 3, no. 2, pp. 73-81, 2013.
[53] C. H. Wang, W. D. Lin, D. T. Bau et al., "Appearance of acanthosis nigricans may precede obesity: an involvement of the insulin/IGF receptor signaling pathway," BioMedicine, vol. 3, no. 2, pp. 82-87, 2013.

[54] T.-Y. Tsai, K.-W. Chang, and C. Y.-C. Chen, "IScreen: world's first cloud-computing web server for virtual screening and de novo drug design based on TCM database@Taiwan," Journal of Computer-Aided Molecular Design, vol. 25, no. 6, pp. 525-531, 2011.

[55] C. Y.-C. Chen, "Weighted equation and rules: a novel concept for evaluating protein-ligand interaction," Journal of Biomolecular Structure and Dynamics, vol. 27, no. 3, pp. 271-282, 2009.

[56] C. C. Lee, C. H. Tsai, L. Wan et al., "Increased incidence of Parkinsonism among Chinese with beta-glucosidase mutation in central Taiwan," BioMedicine, vol. 3, no. 2, pp. 92-94, 2013.

[57] C. Y.-C. Chen, “TCM Database@Taiwan: the world’s largest traditional Chinese medicine database for drug screening In Silico," PLoS ONE, vol. 6, no. 1, Article ID e15939, 2011.

[58] Accelerys, Discovery Studio Client V2. 5, Accelrys, San Diego, Calif, USA, 2009.

[59] B. Xue, R. L. Dunbrack, R. W. Williams, A. K. Dunker, and V. N. Uversky, "PONDR-FIT: a meta-predictor of intrinsically disordered amino acids," Biochimica et Biophysica Acta: Proteins and Proteomics, vol. 1804, no. 4, pp. 996-1010, 2010.

[60] D. J. Diller and K. M. Merz Jr., "High throughput docking for library design and library prioritization," Proteins, vol. 43, no. 2 , pp. 113-124, 2001.

[61] A. C. Wallace, R. A. Laskowski, and J. M. Thornton, "LIGPLOT: a program to generate schematic diagrams of protein-ligand interactions," Protein Engineering, vol. 8, no. 2, pp. 127-134, 1995.

[62] R. A. Laskowski and M. B. Swindells, "LigPlot+: multiple ligandprotein interaction diagrams for drug discovery," Journal of Chemical Information and Modeling, vol. 51, no. 10, pp. 27782786, 2011.

[63] S. Pronk, S. Pall, R. Schulz et al., "GROMACS 4. 5: a highthroughput and highly parallel open source molecular simulation toolkit," Bioinformatics, vol. 29, no. 7, pp. 845-854, 2013.

[64] J. E. Jones, "On the determination of molecular fields. II. From the equation of state of a gas," Proceedings of the Royal Society of London A, vol. 106, no. 738, pp. 463-477, 1924.

[65] J. Tersoff, "Modeling solid-state chemistry: interatomic potentials for multicomponent systems," Physical Review B, vol. 39, no. 8, pp. 5566-5568, 1989.

[66] M. S. Daw, S. M. Foiles, and M. I. Baskes, "The embedded-atom method: a review of theory and applications," Materials Science Reports, vol. 9, no. 7-8, pp. 251-310, 1993.

[67] F. Cleri and V. Rosato, "Tight-binding potentials for transition metals and alloys," Physical Review B, vol. 48, no. 1, pp. 22-33, 1993.

[68] C. Y. Chen and W. I. Tou, "How to design a drug for the disordered proteins?” Drug Discovery Today, vol. 18, no. 19-20, pp. 910-915, 2013.

[69] W. I. Tou, S. S. Chang, C. C. Lee, and C. Y. Chen, "Drug design for neuropathic pain regulation from traditional Chinese medicine," Scientific Reports, vol. 3, article 844, 2013.

[70] W. I. Tou and C. Y. Chen, "May disordered protein cause serious drug side effect?" Drug Discovery Today, vol. 19, no. 4, pp. 367372, 2014.

[71] E. Chovancova, A. Pavelka, P. Benes et al., "CAVER 3. 0: a tool for the analysis of transport pathways in dynamic protein structures," PLoS Computational Biology, vol. 8, no. 10, Article ID e1002708, 2012. 

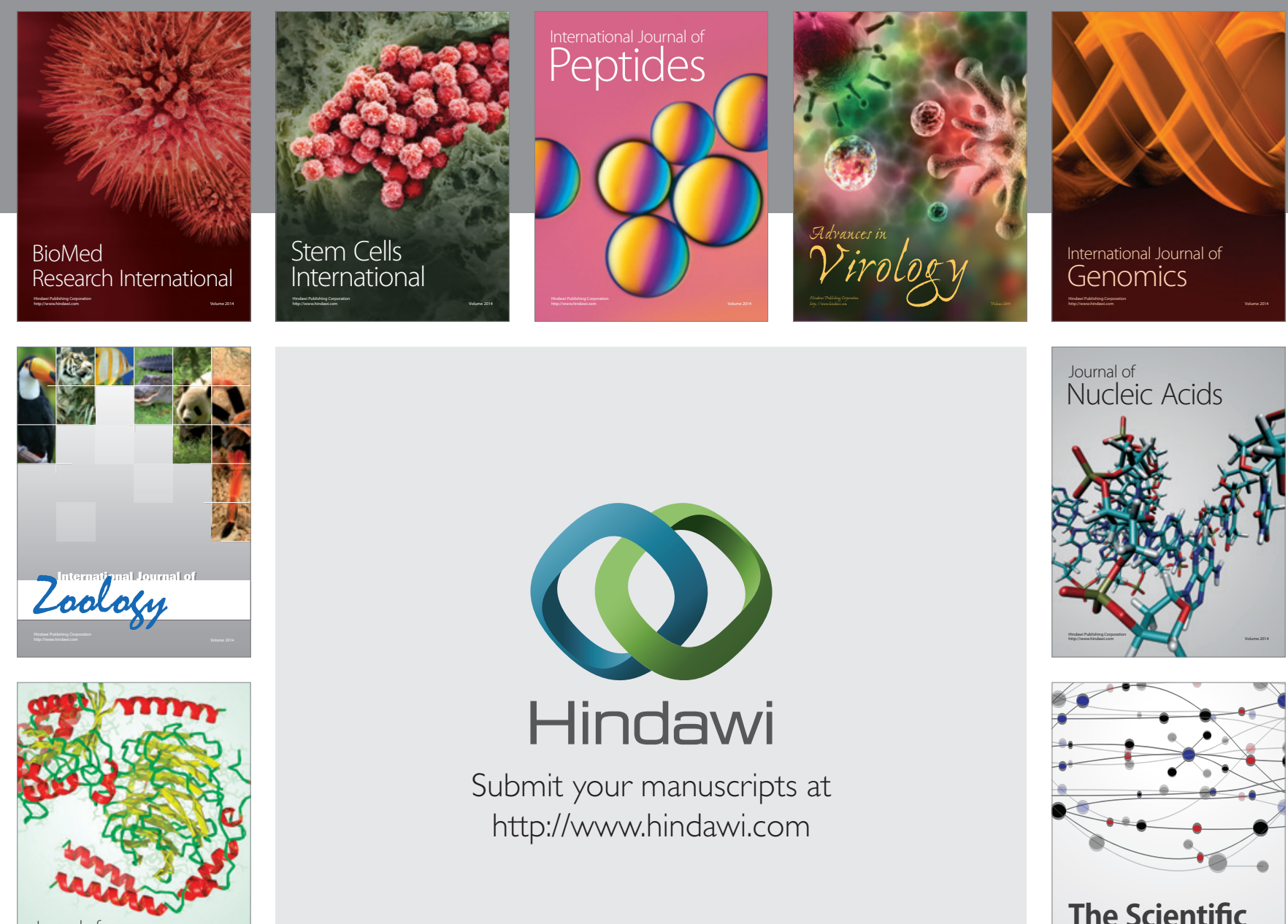

Submit your manuscripts at

http://www.hindawi.com

Journal of
Signal Transduction
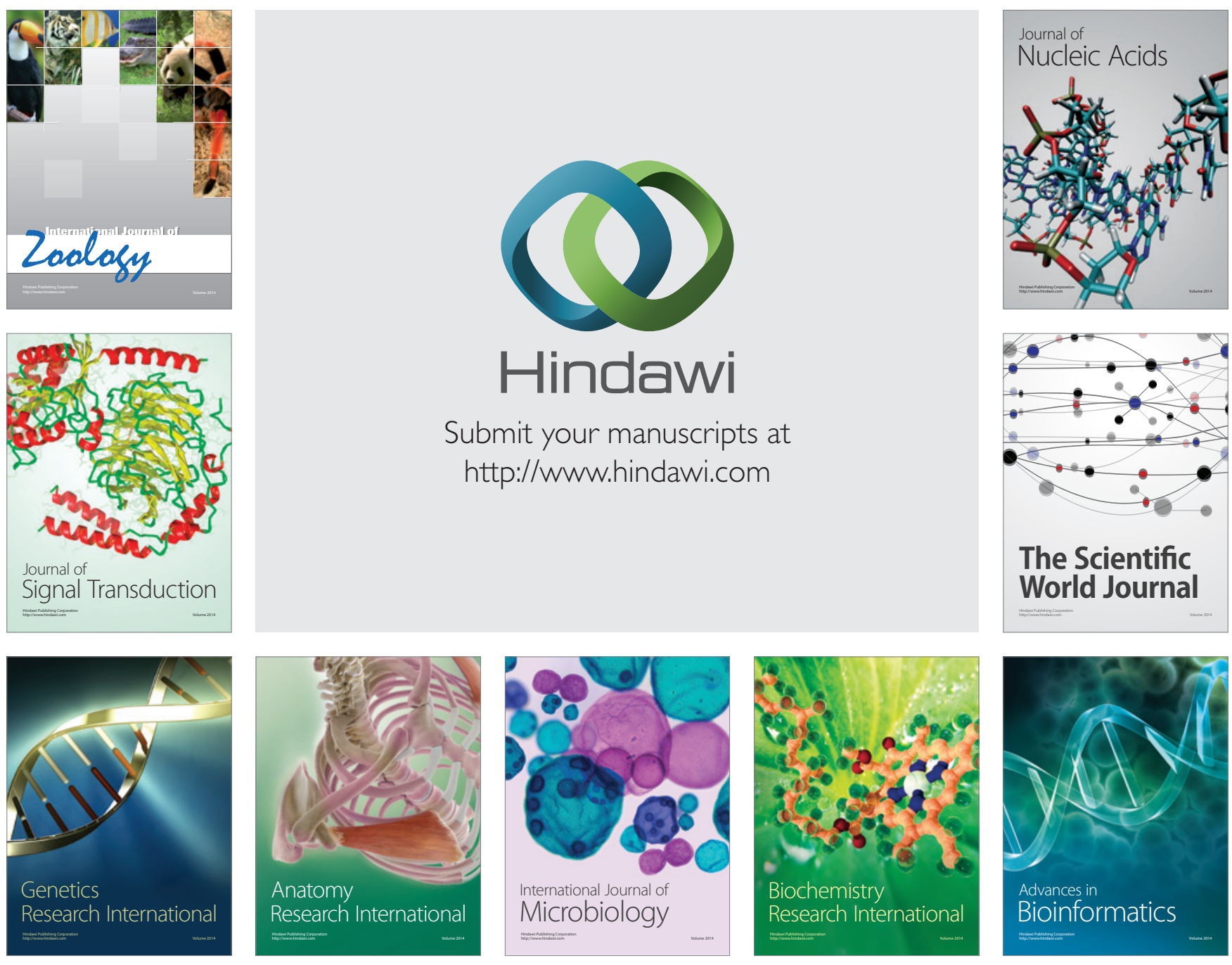

The Scientific World Journal
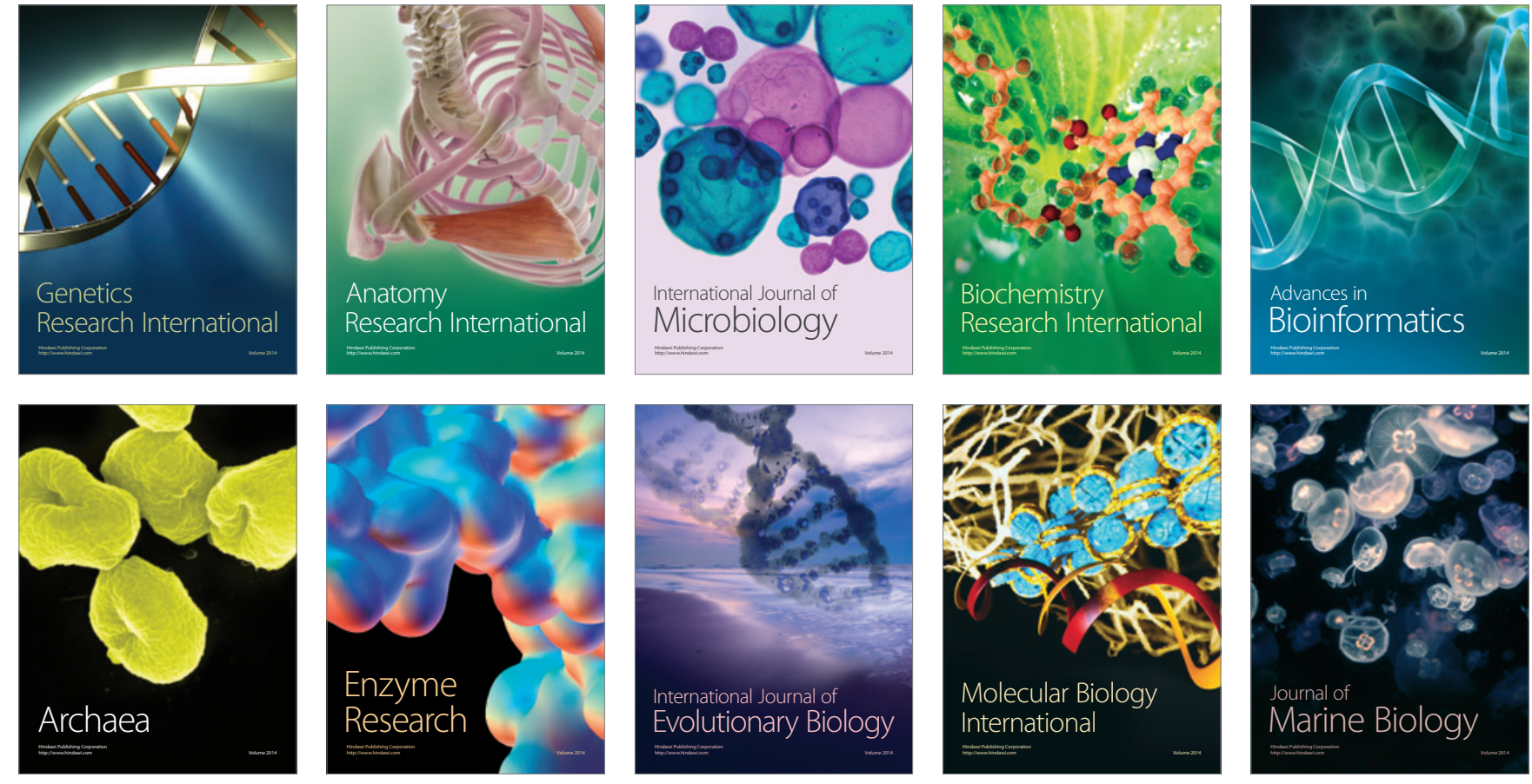